Talanta

June 2018, Volume 183, Pages 201-208

http://dx.doi.org/10.1016/i.talanta.2018.02.051

http://archimer.ifremer.fr/doc/00427/53874/

(C) 2018 Elsevier B.V. All rights reserved.

\title{
3D-printed lab-on-valve for fluorescent determination of cadmium and lead in water
}

\author{
Mattio Elodie ${ }^{1}$, Robert-Peillard Fabien ${ }^{1}$, Vassalo Laurent ${ }^{1}$, Branger Catherine ${ }^{2}$, Margaillan André ${ }^{2}$, \\ Brach-Papa Christophe ${ }^{3}$, Knoery Joel ${ }^{3}$, Boudenne Jean-Luc ${ }^{1}$, Coulomb Bruno ${ }^{1,{ }^{*}}$
}

${ }^{1}$ Aix Marseille Univ, CNRS, LCE, Marseille, France

2 University of Toulon, MAPIEM, La Garde, France

${ }^{3}$ IFREMER, LBCM, Nantes, France

*Corresponding author : Bruno Coulomb, email address : bruno.coulomb@univ-amu.fr

\begin{abstract}
:
In recent years, the development of 3D printing in flow analysis has allowed the creation of new systems with various applications. Up to now, 3D printing was mainly used for the manufacture of small units such as flow detection cells, preconcentration units or mixing systems. In the present study, a new 3D printed lab-on-valve system was developed to selectively quantify lead and cadmium in water. Different technologies were compared for lab-on-valve 3D printing. Printed test units have shown that stereolithography or digital light processing are satisfactory techniques for creating complex lab-onvalve units. The lab-on-valve system was composed of two columns, eight peripheral ports and a central port, and a coil integrating baffles to increase mixing possibilities. A selective extraction of lead was first carried out by TrisKem $\mathrm{Pb}^{\mathrm{TM}}$ Resin column. Then, cadmium not retained on the first column was extracted on a second column of Amberlite ${ }^{\circledR}$ IR 120 resin. In a following step, lead and cadmium were eluted with ammonium oxalate and potassium iodide, respectively. Finally, the two metals were sequentially detected by the same Rhod-5N ${ }^{\mathrm{TM}}$ fluorescent reagent. This $3 \mathrm{D}$ printed lab-on-valve flow system allowed us to quantify lead and cadmium with a linear response from 0.2 to $15 \mu \mathrm{g} . \mathrm{L}-1$ and detection limits of 0.17 and $0.20 \mu \mathrm{g} . \mathrm{L}-1$ for lead and cadmium, respectively, which seems adapted for natural water analysis.
\end{abstract}




\section{Graphical abstract}

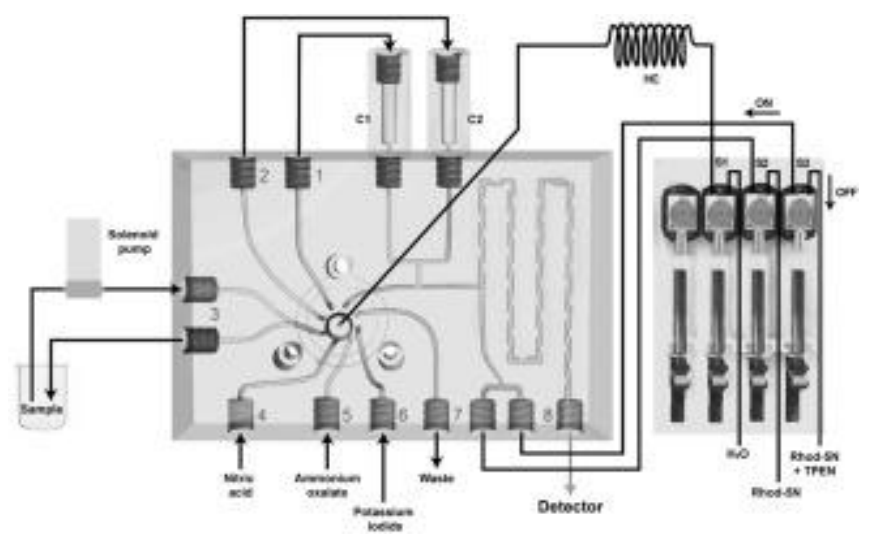

\section{Highlights}

A 3D-printed LOV-MSFIA system is presented. $\mathrm{Pb}^{2+}$ and $\mathrm{Cd}^{2+}$ can be quantified between 0.2 and $15 \mu \mathrm{g} \cdot \mathrm{L}^{-1}$. The LODs obtained $\left(0.20\right.$ and $0.17 \mu \mathrm{g} \cdot \mathrm{L}^{-1}$ for cadmium and lead respectively) are lower than the MAC-EQS as defined by the European regulations $-3 D$ printing of LOV units opens new perspectives for the design of more complex LOV systems.

Keywords : stereolithography, digital light processing, LOV-MSFIA, natural waters 
Introduction

Cadmium and lead are two of the most concerning metals in water in the light of their toxicities and their levels in the environment. Many pollution sources can cause increased levels of $\mathrm{Cd}$ and $\mathrm{Pb}$ : natural sources like volcanic activity [1] and anthropogenic sources which represent the most important impact, such as metallurgy [2], mining operation [3], electronic industry [4], pesticides [5], or even paints [6].

These metals have several impacts on health: cadmium has a half-life in humans of 10 to 35 years [7] and is mainly accumulated in kidney and liver which might lead to deficiencies [8] like the Itai-itai disease, but it can also be found in spleen, brain and blood, resulting in increasing cancers risks. Lead intoxication can lead to many dysfunctions like cardiovascular diseases [9], neurodevelopmental effects or impaired fertility [10]. In the light of these effects, the World Health Organization has recommended a guideline value of $3 \mu \mathrm{g} . \mathrm{L}^{-1}$ and $10 \mu \mathrm{g} . \mathrm{L}^{-1}$ for cadmium and lead respectively in drinking water.

Accordingly, the development of simple, rapid and sensitive methods for on-line and on-site $\mathrm{Cd}$ and $\mathrm{Pb}$ determination in natural waters has attracted widespread attention in modern analytical chemistry.

Flow analysis seems to be appropriate for the development of these type of portable analytic systems: this technology allows decreasing instrumentation size, and reagents and energy 


\section{ACCEPTED MANUSCRIPT}

consumption, which are significant advantages for an on-site system while simplifying the manipulations required for the assays.

Many flow systems with minimal interferences and low detection limits have been developed for the quantification of cadmium and lead in natural waters but most of these systems are coupled with inductively coupled plasma spectroscopy [11] or atomic absorption spectrometry $[12,13]$, detection techniques that are not compatible with portable systems. Sequential Injection-Lab-on-valve (SI-LOV) flow systems, developed by Ruzicka [14], allow one to integrate the various steps of an analytical method in a miniaturized part placed on the head of a selection valve. The lab-on-valve improves repeatability, reliability and robustness of flow systems while being more compact thus facilitating on-site measurements. Some SILOV systems have been developed for solid phase extraction and solid phase detection of metals [15-17]. For lead and cadmium determination, a SI-LOV system has recently been described [18] but the limits of detection $\left(34 \mu \mathrm{g} . \mathrm{L}^{-1}\right.$ and $56 \mu \mathrm{g} \cdot \mathrm{L}^{-1}$ for cadmium and lead respectively) limit the use of the system to a rapid screening of the two metals in contaminated waters.

Until now, the possibilities of LOV creation have been limited by the machining of parts by drilling, embossing or molding, which does not make it possible to integrate all the analysis steps in the LOV. This problem henceforth can be solved by using 3D printing.

3D printing enables one to create three-dimensional object from computer-aided design model by using different printing technologies, and is increasingly used in flow analysis to create tailor-made units: an experimental comparison of three 3D printing technologies used in flow analysis has been carried out to evaluate best performances [19], and many reviews resume emerging applications of 3D printing in microfluidic systems [20-22]. A MSFIA system has recently been developed for the iron speciation with a 3D printed device integrating analyte oxidation, disk-based SPE and analyte complexation [23]. 


\section{ACCEPTED MANUSCRIPT}

Fused Deposition Modeling (FDM) and photo-polymerization processes such as Stereolithography (SLA), Digital Light Processing (DLP) and Polyjet ${ }^{\circledR}$ are the main 3D printing technologies used in flow systems. In SLA and DLP technologies, a unit is created layer by layer from a photopolymer resin, cured by a UV-laser (SLA) or a conventional light source (DLP). SLA and DLP enable formation of units directly in the liquid photopolymer resin tank on a platform that goes up as the layers are printed. In Polyjet ${ }^{\circledR}$ technology, the liquid material is deposited on a build platform and is cured, by the passage of an UV lamp layer after layer. This technology requires the use of a water-soluble support material to fill the voids (tubing, cells, and columns) of the part during printing. This water-soluble support material is then cleaned during post-processing of the printed part.

In this paper, a new 3D printed lab-on-valve is presented and integrated in a MSFIA system for the determination of low levels of $\mathrm{Cd}$ and $\mathrm{Pb}$ in natural waters. The 3D-printed LOV is constituted of 8 peripheral ports and a central port connected to the 3-way valve of a syringe and contains two columns used for solid phase extraction and preconcentration of lead and cadmium, a mixing coil with baffles to break flow and increase turbulences in order to increase mixing capabilities, and a fluorescence detection cell. The analytical procedure developed is first based on the selective extraction of lead by the TrisKem $\mathrm{Pb}$ resin ${ }^{\circledR}$ (this resin has been already studied and included in a 3D-printed flow system for determination of lead in natural waters in a previous study [24]). In a second step, cadmium is extracted on Amberlite ${ }^{\circledR}$ IR 120 exchange resin and selectively eluted with potassium iodide. The quantification of the two metals is based on the use of the Rhod-5N ${ }^{\mathrm{TM}}$ fluorescent reagent. The MSFIA-LOV developed system has been validated on real river water samples.

2. Materials and methods

\subsection{Reagents}




\section{ACCEPTED MANUSCRIPT}

All chemicals used were of analytical grade and used without further purification. Solutions were prepared with ultra-pure water (Millipore, resistivity $>18 \mathrm{M} \Omega \mathrm{cm}$ ) and stocked in high density polyethylene or Teflon flasks. Cadmium and lead standard solutions were prepared by dilution of commercial 1 g.L. $\mathrm{L}^{-1}$ AAS stock solutions (Fisher Chemical, USA) and stabilized with $1 \% \mathrm{v} / \mathrm{v}$ nitric acid trace metal grade (Fisher Chemical, USA). Calcium solution was prepared by dissolving anhydrous calcium chloride (Alfa Aesar, Germany) in ultra-pure water. A multi-metal solution $\left(10 \mu \mathrm{mol} . \mathrm{L}^{-1}\right.$ for each metal $)$ was prepared by diluting and mixing eleven commercial AAS stock solutions of aluminium, cadmium, calcium, cobalt, chromium, copper, iron, lead, magnesium, nickel and zinc, at 1 g.L. $\mathrm{L}^{-1}$ (Fisher Chemical, USA) in ultra-pure water.

Cadmium and lead extraction were respectively carried out with the Amberlite ${ }^{\circledR}$ IR 120

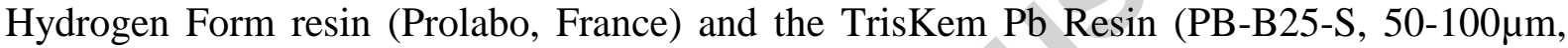
TrisKem, France). Eluents were prepared from potassium iodide (Sigma-Aldrich, USA) for cadmium and from ammonium oxalate (Prolabo, France) for lead. Other eluents tested were prepared from trace metal grade nitric acid (Fisher Chemical, USA) and ammonium nitrate (Prolabo, France).

For detection, a $0.2 \mu \mathrm{mol} . \mathrm{L}^{-1}$ solution of Rhod-5N tripotassium salt (Fisher Chemical, USA) was prepared in a 10 mmol.L $\mathrm{L}^{-1}$ 3-(N-morpholino)propanesulfonic acid (MOPS) buffer solution at $\mathrm{pH}=7$ (Sigma-Aldrich, USA). To take into account the interferences related to the presence of calcium in the samples, a two-step analytical procedure was developed and required the addition of a $3 \mu$ mol. $\mathrm{L}^{-1}$ masking agent solution of $\mathrm{N}, \mathrm{N}, \mathrm{N}^{\prime}, \mathrm{N}^{\prime}$-tetrakis-(2pyridylmethyl)ethylenediamine (TPEN) (Sigma-Aldrich, USA) to the Rhod-5N reagent.

\subsection{Apparatus}

\subsubsection{Metal analysis}




\section{ACCEPTED MANUSCRIPT}

The extraction and elution steps of cadmium, lead and interfering metals on Tris Kem $\mathrm{Pb}$ resin and Amberlite ${ }^{\circledR}$ IR 120 resin were studied by inductively coupled plasma-atomic emission spectrometry (ICP-AES) with a Jobin YVON JY2000 Ultratrace spectrometer, equipped with

a CMA spray chamber and a Meinhard R50-C1 glass nebuliser. Determinations were performed with the following settings: power $1000 \mathrm{~W}$, pump speed $20 \mathrm{~mL} \cdot \mathrm{min}^{-1}$, plasma flow rate $12 \mathrm{~L} \cdot \mathrm{min}^{-1}$, coating gas flow rate $0.15 \mathrm{~L} \cdot \mathrm{min}^{-1}$, nebuliser flow rate $1.08 \mathrm{~L} \cdot \mathrm{min}^{-1}$ and nebuliser pressure 2.6 bar.

Graphite furnace atomic absorption spectrometry (GF-AAS) was used to quantify lead in real samples. The measurements were carried out on a Thermo Scientific ICE3500 (USA) atomic absorption spectrometer equipped with a lead hollow-cathode lamp operated at $10 \mathrm{~mA}$ (wavelength of $217 \mathrm{~nm}$ ). Argon flow was $0.2 \mathrm{~L} \cdot \mathrm{min}^{-1}$ except during atomisation step (no flow). The furnace settings were as follow: drying at $110{ }^{\circ} \mathrm{C}$, ramp for $9 \mathrm{~s}$, hold for $35 \mathrm{~s}$; cracking at $800{ }^{\circ} \mathrm{C}$, ramp for $5 \mathrm{~s}$, hold for $20 \mathrm{~s}$; atomising at $1200{ }^{\circ} \mathrm{C}$, ramp for $1 \mathrm{~s}$ and $3 \mathrm{~s}$ hold; cleaning at $2500{ }^{\circ} \mathrm{C}$, no ramp and $3 \mathrm{~s}$ hold.

\subsubsection{Flow system}

The MSFIA-LOV system used in this study is shown in Fig. 1. Different LOV units were designed with Rhinoceros® ${ }^{\circledR} .0$ 3D software (Robert McNeel \& Associates Europe, Spain). Various 3D printers were tested to fabricate units: the Form1+ printer (Formlabs, USA), the Object500 Connex 3 printer (Stratasys, USA) and the Miicraft 100 printer (Miicraft, Rays Optics Inc., Taiwan). The three printers were used with acrylic transparent resins that had chemical resistance properties closed to those of poly(methyl methacrylate) (PMMA) with good resistance to common diluted acids. The 3D printed LOV part was fixed on an 8-ports multiposition selection valve module (Sciware Systems SL, Spain) and coupled with a multisyringe burette module with programmable speed (Multiburette 4S, Crison Instruments, 


\section{ACCEPTED MANUSCRIPT}

Spain) equipped with three $5 \mathrm{~mL}$ glass syringes (Hamilton, Switzerland). Each syringe was connected to a 3-way solenoid valve (S1, S2, S3) for multicommutation steps. A continuous renewal of sample was done by a solenoid micro-pump (Bio-ChemValve Inc., USA) that had a stroke volume of $20 \mu \mathrm{L}$ and a high frequency of 250 cycles. $\min ^{-1}$.

For the detection, a Kontron Instruments SFM25 fluorometer (Kontron, Germany) was used with a Hellma ${ }^{\mathrm{TM}}$ quartz UV flow cell. It should be noted that the spectrofluorimeter used in this study can be easily replaced by a more compact detection system based on the use of a laser diode for excitation and a photodiode for detection.

The whole system, except the fluorometer, was controlled by AutoAnalysis 5.0 software (Sciware Systems SL, Spain).

\subsection{Lab-on-valve unit}

The LOV had the following dimensions: height $66 \times$ width $100 \mathrm{x}$ depth $17 \mathrm{~mm}$. It was composed by eight peripheral ports and a central port connected to S1 via a holding coil (Figure 1). Channel inner diameters were $1.2 \mathrm{~mm}$, except for mixing coil which was $0.8 \mathrm{~mm}$ i.d. at the narrowest point. Two ports (1 and 2) were externally linked on the top of columns (C1 and $\mathrm{C} 2$ ) by a $0.8 \mathrm{~mm}$ i.d. PTFE tubing to introduce sample and reagents. Both columns were 3D printed and were independent of the LOV system so that they could be easily changed (the two columns were simply screwed to two LOV inputs). C1 and C2 were respectively filled with $50 \mathrm{mg}$ of TrisKem $\mathrm{Pb}$ resin for lead extraction and $50 \mathrm{mg}$ of Amberlite ${ }^{\circledR}$ IR 120 for cadmium preconcentration. These columns were linked to a $184 \mathrm{~mm}$ long mixing coil (connected to the detector via port 8). This mixing coil was designed with 2 mm wide baffles in order to break flow and increase turbulences, therefore increasing mixing capabilities of the coil. A two-way microconduit allowed the introduction of detection reagents. 


\section{ACCEPTED MANUSCRIPT}

Ports 3 and 7 were employed for sample introduction and waste, respectively. The remaining peripheral ports (port 4, 5 and 6) were used for the introduction of the eluents: nitric acid (4), ammonium oxalate (5) and potassium iodide (6).

\subsection{Analytical procedure}

The complete analytical sequence for cadmium and lead preconcentration and detection is listed in Table 1 and can be summarized as follows:

1. Conditioning of TrisKem $\mathrm{Pb}$ resin with $\mathrm{HNO}_{3} 0.05$ mol. $\mathrm{L}^{-1}$ : the central port $(\mathrm{CC})$ of the LOV is connected to the peripheral port 4 to aspirate $4 \mathrm{~mL}$ of nitric acid in holding coil (HC) which are propelled towards $\mathrm{C} 1$ via port 1.

2. Sample introduction: the sample is loaded in HC (port 3) and then dispensed towards $\mathrm{C} 1$ (port 1) at a flow rate of $4 \mathrm{~mL} \cdot \mathrm{min}^{-1}$. Once the lead retained onto TrisKem $\mathrm{Pb}$ resin (C1), this lead-extracted sample is reaspirated via port 8 in the $\mathrm{HC}$ and dispensed through C2 (port 2) for cadmium extraction on the Amberlite ${ }^{\circledR}$ IR 120.

3. Elution and detection of cadmium: potassium iodide $\left(0.15 \mathrm{~mol} . \mathrm{L}^{-1}\right)$ and Rhod-5N $(0.2$ $\mu$ mol. $\mathrm{L}^{-1}$ ) are simultaneously dispensed respectively through $\mathrm{C} 2$ (port 2) to eluate extracted cadmium and at the inlet of the mixing coil (S2). Measurement is based on the peak height with $\lambda \mathrm{ex}=550 \mathrm{~nm}$ and $\lambda \mathrm{em}=575 \mathrm{~nm}$.

4. Second introduction of sample: steps 3 to 6 are repeated. A total volume of $10 \mathrm{~mL}$ is thus dispensed through the TrisKem $\mathrm{Pb}$ resin $(\mathrm{C} 1)$. The aim of this second sample introduction is to quantify interference of calcium for cadmium determination. During the detection step, potassium iodide (port 6) solution and Rhod-5N+TPEN reagent (S3) are simultaneous dispensed. TPEN is added to Rhod-5N reagent to complex cadmium and detect calcium specifically. The interference generated by calcium can thus be determined. 


\section{ACCEPTED MANUSCRIPT}

5. Elution and detection of lead: the TrisKem $\mathrm{Pb}$ resin $(\mathrm{C} 1)$ is washed with nitric acid solution $\left(0.05 \mathrm{~mol} . \mathrm{L}^{-1}\right)$ to eliminate potential interfering species extracted by the resin. Ammonium oxalate solution $\left(0.025\right.$ mol. $\left.\mathrm{L}^{-1}\right)$ and Rhod-5N are simultaneously dispensed to eluate and detect lead.

\section{Results and discussion}

\subsection{D printing of the LOV unit}

The first step to print a lab-on-valve, after its conception on a 3D software, was to select a suitable technology. The printing of LOV units requires a good resolution on the 3 axes XYZ and a high precision. Several printers have thus been tested to find the most suitable for the manufacture of LOV units.

Fused Deposition Modeling (FDM), the most used technology in 3D printing, is not suitable for creating fluidic systems, in the light of difficulties to form small tubings and smooth surface without post-treatment. The same statement could be done with Selective Laser Sintering (SLS), in which the grain size of powdered materials limits the resolution and gives a porous unit.

Photopolymerisation technologies are therefore recommended for LOV printing: stereolithography (SLA), digital light processing (DLP) and Polyjet® technology provide sufficient performance to print complex flow units. These three technologies were therefore studied to print the LOV unit used in this study. Figure 2 shows photos of the printed LOV units.

\subsubsection{Polyjet@ technology}

Several LOV units have been printed with Polyjet ${ }^{\circledR}$ technology using an Object500 Connex 3 printer, a Veroclear® transparent acrylic/epoxy resin and a SUP706 soluble support material 


\section{ACCEPTED MANUSCRIPT}

(Stratasys, USA). Considering the high cost of the printer (more than $200 \mathrm{k} €$ ), the fabrication of the piece was subcontracted to a specialized company (Maquette74, France). In this technique, photopolymer drops are deposited and cured by an UV lamp and the printing of micro conduits of LOV unit requires a water-soluble support material. Three 3D-printed LOV units have been compared: one without mixing coil, one with classical coil, and another with a mixing coil containing baffles, to increase turbulences and mixing capacities.

The two LOV units with mixing coils had clogging problems (Figures 2.1 and 2.3). Note that in figures 2.1 and 2.3 the photos have been retouched and the clogged parts have been contrasted in red for a better understanding. In the black and white version of the photos, the clogged tubing sections appear lighter than the properly formed tubings. Original unretouched photos are presented in supplementary materials (Fig. S1). In these printed LOV units, watersoluble support could not be completely removed at the end of printing processing, even with mechanical (brushing) or chemical treatment (solubilisation by $\mathrm{NaOH}$ solution). The cleaning of coil tubing (with or without baffles) was very difficult and tubings remained clogged after printing and cleaning.

However, the LOV unit without mixing coil did not have clogging problems: channels were clean and the surface unit was smooth, which was an advantage for the area in contact with the Teflon disk in order to limit leaks. Therefore, Polyjet ${ }^{\circledR}$ technology could be recommended to print simple LOV units, without mixing coil or complex tubings, because of its high precision, the robustness of printed pieces and its high quality finish.

\subsubsection{Stereolithography}

The Form1+ printer has been used in lab to evaluate performances of stereolithography to print a LOV unit. This printer costs about $3.5 \mathrm{k} €$ and the units were printed with clear acrylic 


\section{ACCEPTED MANUSCRIPT}

resin FLGPCL02. In this technology, the unit is formed directly in the tank of the liquid photopolymer and water-soluble support is thus not required to form tubing.

The same three LOV units were 3D printed by stereolithography (resolution of $100 \mu \mathrm{m}$, printing time 6 hours) using the same .stl files previously used with Polyjet ${ }^{\circledR}$ technology printing. The results did not show any clogging problem (Figure 2.2). The eight positions of the LOV were correctly formed, however the surface was uneven and many defects were observed at several layers of the units resulting in microcracks in the printed part.

Furthermore, deformations of printed units were observed: this problem is frequently encountered in SLA due to resin shrinkage, which causes leaks between the positions of the LOV, and furthermore, optical pathlengths may exhibit significant deformation preventing optimal detection. Some printer software can take this issue into account by proposing $\mathrm{X}$ and $\mathrm{Y}$ axis compensation, but this parameter was not found in the Preform software used to control the Form1+. A smaller resolution was able to improve the precision of LOV positions (25 or $50 \mu \mathrm{m}$ ), but the printing time was longer (20 and 10 hours respectively) which could increase the risk of printing problems like unit's fall in resin tank or incomplete formation. Unsuccessful printing tests with 25 and $50 \mu \mathrm{m}$ resolution led us to limit the resolution to 100 $\mu \mathrm{m}$ for lab-on-valve fabrication. Besides, a post-treatment was necessary to obtain a real smooth area in contact with the Teflon disk of the selection valve.

\subsubsection{Digital light processing (DLP)}

The disadvantages of previous technologies to print the designed LOV unit led us to study digital light processing. For this technology, the unit formation is the same as in stereolithography, however the resin is not progressively photo-polymerized by a laser like in stereolithography but a projector displays directly an UV image of each layer to photopolymerize resin on the platform. 


\section{ACCEPTED MANUSCRIPT}

Different units were printed in lab with the Miicraft 100 printer (printer price is about 10k euros) and the BV-007 transparent acrylic resin: the printed parts showed a smoother surface with faster printing (with a resolution of $20 \mu \mathrm{m}$, printing time 5 hours) than in stereolithography (Figure 2.4). Moreover, tubings formation were more accurate and it has been possible to decrease the inner diameter to $0.8 \mathrm{~mm}$ vs $1.2 \mathrm{~mm}$ in stereolithography. The area in contact with the Teflon disk of the selection valve was perfectly formed and no leak has been observed.

In conclusion of this part, Figure 2 summarized the observations made for each technology: the Polyjet technology® did not allow the printing of a mixing coil without clogging problem (picture 1 and 3). At the opposite, the stereolithography could print an unclogged LOV unit but with an uneven and harsh surface (picture 2), resulting in a bad positioning of the LOV part on the valve rotor and causing leakage of the reagents used and deterioration of the Teflon disk of the valve. The digital light processing gathered the advantages of the two previous technologies: the printed surface was smooth and tubing were well-formed (picture 4). In these conditions, DLP appeared to be the more adapted technology to print a LOV unit with mixing coil. However, to work without mixing coil, the Polyjet technology® showed better performances than DLP.

\subsection{Lead determination}

The procedure for lead determination in natural waters has already been described in a previous study [24]. The determination was based on selective solid phase extraction of lead on a commercial resin (TrisKem $\mathrm{Pb}$ resin) in $\mathrm{HNO}_{3} 0.05$ mol. $\mathrm{L}^{-1}$. For this study, the extraction of lead has been studied at $\mathrm{pH} 7$ in order to reuse the sample for cadmium determination.

The results showed that TrisKem $\mathrm{Pb}$ resin extracted lead more than $90 \%$ at $\mathrm{pH} 7$, a result very close to that obtained in the presence of nitric acid (Fig S2). Most of cations, including 


\section{ACCEPTED MANUSCRIPT}

calcium and magnesium, were not retained by the resin, except for iron that was partially extracted $(<20 \%)$. The washing step with $\mathrm{HNO}_{3} 0.05$ mol.L ${ }^{-1}$ has been previously studied [24] and allowed elimination of $75 \%$ of iron extracted. Lead elution was carried out by ammonium oxalate 0.025 mol. $\mathrm{L}^{-1}$ to extract more than $90 \%$ of lead. Lead was then detected by the Rhod$5 \mathrm{~N}$ reagent and the remaining iron did not interfere in the measurement.

\subsection{Cadmium determination}

To measure low levels of cadmium in natural waters, a sensitive and selective reagent for detection has to be used. In addition, the use of the same reagent for the detection of lead and cadmium makes it possible to simplify the flow system. Several chromogenic reagents for a spectrophotometric detection have been considered, like 4-(2-pyridylazo)resorcinol (PAR) or dithizone, however, none of them allowed a selective detection at very low concentrations. Fluorescent reagents have also been examined: 8-hydroxyquinoline-5-sulfonic acid [25] shows major interferences that could disturb cadmium measurement. Rhod-5N [26] appears to meet the requirements of selectivity and sensitivity and has been used in this study. Although Rhod-5N has some selectivity for cadmium, some other cations can be detected with this reagent. Calcium, lead, copper, iron and zinc are the main interfering cations in natural waters. In this study lead is extracted beforehand by TrisKem $\mathrm{Pb}$ resin and copper and iron do not react with Rhod-5N. These cations will not interfere in the measurement of cadmium. However, it was necessary to find a resin allowing the selective extraction of cadmium to avoid calcium and zinc interferences.

\subsubsection{Cadmium selective preconcentration}

Several commercial cation exchange resins have been studied. Two resins have been particularly tested: an iminodiacetic acid resin, the Amberlite ${ }^{\circledR}$ IRC 748, known for its high selectivity for heavy metals cations [27], and an acidic resin, the Amberlite ${ }^{\circledR}$ IR 120 , which 


\section{ACCEPTED MANUSCRIPT}

could be selective depending on the eluent used [28]. Extraction rates of these resins were studied using a multi-metal solution at $\mathrm{pH}=7$, with a concentration of $10 \mu \mathrm{mol} . \mathrm{L}^{-1}$ for each metal and a flow rate of $2 \mathrm{~mL} \cdot \mathrm{min}^{-1}$.

The results obtained with the Amberlite ${ }^{\circledR}$ IRC 748 were unsatisfactory: only $48 \%$ of cadmium were extracted, while for interfering cations, $33 \%$ of calcium and $80 \%$ of zinc were extracted. In addition, the various eluents tested (nitric acid, potassium iodide, ammonium nitrate and ammonium oxalate) did not improve the selectivity for cadmium over interfering cations.

For the Amberlite ${ }^{\circledR}$ IR 120 , the extraction step was more efficient for cadmium with an extraction of $65 \%$, but also for calcium and zinc, with an extraction yield of 70 and $85 \%$ respectively. However, the elution step was crucial for the selective preconcentration of cadmium. Many eluents at different concentrations have been tested and the most significant results are resumed in Figure 3. Elution with nitric acid, ammonium nitrate and ammonium oxalate did not present any selectivity for cadmium. In contrast, potassium iodide (KI 0.15 mol.L $L^{-1}$ ) showed a significant selectivity for cadmium: $95 \%$ of cadmium was eluted, against $15 \%$ of calcium and $18 \%$ of zinc. Three concentrations of potassium iodide $(0.05,0.15$ and 0.30 mol. $\mathrm{L}^{-1}$ ) have then been tested in order to optimize cadmium elution. Less than $10 \%$ of cadmium and other metals were eluted with $\mathrm{KI} 0.05$ mol. $\mathrm{L}^{-1}$. Cadmium was quantitatively eluted at a rate of $95 \%$ with 0.15 and 0.30 mol. $\mathrm{L}^{-1} \mathrm{KI}$ but with this last concentration, $30 \%$ of calcium and about $40 \%$ of other metals such as $\mathrm{Cu}$ and Fe were also eluted. Thus, a concentration of 0.15 mol. $\mathrm{L}^{-1}$ of potassium iodide was the most adequate to quantitatively elute cadmium while limiting elution of interfering cations. Note that lead was previously extracted by Triskem- $\mathrm{Pb}$ resin and therefore do not interfere in cadmium measurement.

Extraction and elution flow rates on Amberlite ${ }^{\circledR}$ IR 120 were tested between 1 and 6 mL.min ${ }^{-}$

${ }^{1}$. Results showed that the best compromise between extraction/elution rates and analysis 


\section{ACCEPTED MANUSCRIPT}

duration was obtained when flow rate was fixed at $4 \mathrm{~mL} \cdot \mathrm{min}^{-1}$. Flow rates above $4 \mathrm{~mL} \cdot \mathrm{min}^{-1}$ resulted in small bubbles introduction in the flow system.

\subsubsection{Interfering cations during cadmium detection}

The extraction and elution steps on Amberlite ${ }^{\circledR}$ IR 120 eliminated the majority of interfering cations. Less than $15 \%$ zinc was extracted and eluted and, given zinc levels usually found in natural waters and the response of zinc with Rhod-5N, this element does not interfere with the measurement of cadmium.

With the previously described procedure, $10 \%$ of calcium was finally extracted and eluted: in the light of the high calcium levels usually found in natural waters, this quantity could still interfere during the cadmium detection step. In these conditions, a procedure to quantify separately calcium and determinate a signal correction for cadmium determination has been established.

After a first step of extraction and elution of the two resins, cadmium and calcium are quantified by Rhod-5N reagent. The fluorescence signal obtained thus corresponds to the concentration of cadmium in the sample to which is added the interference of calcium. The sample is then injected into the flow system a second time for a new extraction/elution cycle on both resins. A masking agent solution of $\mathrm{N}, \mathrm{N}, \mathrm{N}^{\prime}, \mathrm{N}^{\prime}$-tetrakis-(2pyridylmethyl)ethylenediamine (TPEN) is then added to Rhod-5N reagent and used to complex cadmium eluted [29]. The complex cadmium-TPEN has a stability constant higher than those of cadmium-Rhod-5N [26,30] ( $\left.\log \mathrm{K}_{\mathrm{Cd}-\mathrm{TPEN}}=17 ; \log \mathrm{K}_{\mathrm{Cd}-\mathrm{Rhod}-5 \mathrm{~N}}=8.85\right)$. The fluorescence signal obtained thus allow the specific quantification of calcium in sample. From this value, the fluorescence signal obtained previously for the sum of cadmium and calcium can be corrected, and the cadmium concentration can be determined separately. This correction can be applied to correct calcium interference up to $400 \mathrm{mg} . \mathrm{L}^{-1}$. 


\section{ACCEPTED MANUSCRIPT}

\subsection{Analytical features}

Main analytical features of the system developed are summarized in Table S1 (Supplementary Materials). For cadmium analysis, a calibration curve has been constructed with a sample volume of $5 \mathrm{~mL}$. Domain range was linear between 0.2 and $15 \mu \mathrm{g} . \mathrm{L}^{-1}$, with a limit of detection (LOD; $3 \sigma ; n=10)$ of $0.2 \mu \mathrm{g} . \mathrm{L}^{-1}$ and a coefficient of variation $(\mathrm{CV} ; \mathrm{n}=8$ ) of $3.0 \%$. For lead, a sample volume of $10 \mathrm{~mL}$ has been used, and a linear domain range has been obtained between 0.17 and $20 \mu \mathrm{g} . \mathrm{L}^{-1}$, with a LOD of $0.17 \mu \mathrm{g} . \mathrm{L}^{-1}$ and a CV of $6.2 \%$. The sample volume can be increased to improve the detection limit and thus allow the analysis of fresh waters with very low concentrations of lead and cadmium, but to avoid interferences, the calcium content should not exceed $0.4 \mathrm{mg} \cdot \mathrm{mL}^{-1}$ in the sample. The complete analysis time for the sequential determination of cadmium and lead is 18 minutes allowing the analysis of 3 samples per hour.

Santos et al. [18] have recently compared sequential injection methods for the biparametric determination of cadmium and lead in water samples. In this study this comparison has been extended to other flow systems and updated. Main analytical features of these previously reported flow systems are compared in Table 2 with analytical performances of the proposed 3D-printed lab-on-valve system. Some of these works required an atomic absorption spectrometer as a detector (with or without preconcentration step), resulting in low limits of detection $[31,32,33]$ but these detection techniques are not compatible with compact systems. On another hand, some systems based on voltammetric techniques show good limit of detection with large dynamic range and use of compact detection systems [34,35] but require complex protocols for the preparation of electrodes. Systems using spectrometry as a detection method have high detection limits [36] and the only LOV system to our best knowledge that has been developed for the biparametric detection of cadmium and lead has thus been applied to the screening of these metals in contaminated waters [18]. The MSFIA- 


\section{ACCEPTED MANUSCRIPT}

LOV with fluorimetric detection proposed in this study makes it possible to find a compromise between the criteria of sensitivity, simplicity and cost. The LODs obtained $(0.20$ and $0.17 \mu \mathrm{g} . \mathrm{L}^{-1}$ for cadmium and lead respectively) are lower than the MAC-EQS (maximal allowable concentration-environmental quality standards) as defined by the European regulations [37] (0.45 and 7.2 $\mu \mathrm{g} . \mathrm{L}^{-1}$ in inland surface waters for cadmium and lead respectively) and thus allow determinations of lead and cadmium in natural waters.

\subsection{Validation}

To validate the 3D printed LOV-MSFIA system, three samples of natural waters have been collected in different locations in the Marseille city area (south-east of France). The samples were filtered on a $0.45 \mu \mathrm{m}$ polyethersulfone membrane and then UV-photooxidized at $254 \mathrm{~nm}$ during 30 minutes before analysis allowing liberation of cadmium and lead linked to natural organic ligands, inorganic ligands or even to anthropogenic organic ligands. The samples were analyzed in duplicate by the developed 3D printed LOV-MSFIA system and by AAS. The results are summarized in Table 3 . The values obtained by the two methods were consistent. For lead, the mean difference between the two methods was $1.8 \%$, (min $-6.8 \%$; $\max 7.3 \%$ ). The results obtained for lead determination by the proposed system were compared ( $t$ test) with the reference method values (AAS) and no significant differences at the 95\% confidence level were found. For cadmium, as the levels were below the LOD, samples were spiked to $5 \mu \mathrm{g} . \mathrm{L}^{-1}$. The results show an average underestimation of the cadmium content of $13 \%$. These results can be explained by the developed procedure which requires signal correction as a function of calcium concentration.

\section{Conclusion}




\section{ACCEPTED MANUSCRIPT}

A 3D printed LOV-MSFIA system has been developed to quantify lead and cadmium in natural waters. Many 3D printing technologies have been tested to create the LOV unit, and digital light processing seems to be the most adapted. Lead was selectively extracted on Triskem $\mathrm{Pb}$ resin and eluted with ammonium oxalate. Cadmium was preconcentrated on Amberlite ${ }^{\circledR}$ IR 120 and selectively eluted with potassium iodide. These two metals were detected with Rhod-5N fluorescent reagent. Detection limits obtained $\left(0.20 \mu \mathrm{g} . \mathrm{L}^{-1}\right.$ for cadmium and $0.17 \mu \mathrm{g} . \mathrm{L}^{-1}$ for lead) were compatible with analysis of lead and cadmium in fresh or brackish waters. The demonstration of the use of 3D printing for the manufacture of LOV units opens new perspectives for the design of more complex LOV systems.

\section{Acknowledgment}

This work was included in the project "Lab-on-Ship" funded by the French Research Agency (ANR-14-CE04-0004).

Figure captions

Figure 1. MSFIA-LOV system used for cadmium and lead determination with $\mathrm{C} 1$ column for lead extraction and $\mathrm{C} 2$ column for cadmium.

Figure 2. Mixing coils printed with different technologies: Polyjet (1;3), Stereolithography (2), DLP (4).

Figure 2. Elution rate of a multi-metal solution $\left(10 \mu \mathrm{mol}^{-\mathrm{L}^{-1}}\right.$ for each metal) on Amberlite $\AA$ IR $120 \mathrm{H}$ with different eluents.

\section{References}




\section{ACCEPTED MANUSCRIPT}

[1] R. Vigneri, P. Malandrino, F. Gianì, M. Russo, P. Vigneri, Heavy metals in the volcanic environment and thyroid cancer, Molecular and Cellular Endocrinology. 457 (2017) 73-80. doi:10.1016/j.mce.2016.10.027.

[2] X. Shao, H. Cheng, Q. Li, C. Lin, Anthropogenic atmospheric emissions of cadmium in China, Atmospheric Environment. 79 (2013) 155-160. doi:10.1016/j.atmosenv.2013.05.055.

[3] M.P. Taylor, S.A. Mould, L.J. Kristensen, M. Rouillon, Environmental arsenic, cadmium and lead dust emissions from metal mine operations: Implications for environmental management, monitoring and human health, Environ. Res. 135 (2014) 296-303. doi:10.1016/j.envres.2014.08.036.

[4] M. Pecht, Y. Fukuda, S. Rajagopal, The impact of lead-free legislation exemptions on the electronics industry, IEEE Transactions on Electronics Packaging Manufacturing. 27 (2004) 221-232. doi:10.1109/TEPM.2004.843150.

[5] H. Galal- Gorchev, Dietary intake of pesticide residues: Cadmium, mercury, and lead, Food Additives and Contaminants. $8 \quad$ (1991) 793-806. doi:10.1080/02652039109374038.

[6] P. Mushak, Chapter 26 - Lead Regulation and Regulatory Policies: Lead in Paint, in: Trace Metals and Other Contaminants in the Environment, Elsevier, 2011: pp. 841873. doi:10.1016/B978-0-444-51554-4.00026-2.

[7] WHO, Cadmium, WHO. (n.d.). http://www.who.int/ipcs/assessment/public_health/cadmium/en/ (accessed December $8,2017)$.

[8] A. Wilk, E. Kalisińska, D.I. Kosik-Bogacka, M. Romanowski, J. Różański, K. Ciechanowski, M. Słojewski, N. Łanocha-Arendarczyk, Cadmium, lead and mercury 


\section{ACCEPTED MANUSCRIPT}

concentrations in pathologically altered human kidneys, Environmental Geochemistry and Health. 39 (2017) 889-899. doi:10.1007/s10653-016-9860-y.

[9] S.C. Larsson, A. Wolk, Urinary cadmium and mortality from all causes, cancer and cardiovascular disease in the general population: systematic review and meta-analysis of cohort studies, Int J Epidemiol. 45 (2016) 782-791. doi:10.1093/ije/dyv086.

[10] WHO, Lead poisoning and health, WHO. (n.d.). http://www.who.int/mediacentre/factsheets/fs379/en/ (accessed November 10, 2016).

[11] S. Cerutti, M.F. Silva, J.A. Gásquez, R.A. Olsina, L.D. Martinez, On-line preconcentration/determination of cadmium in drinking water on activated carbon using 8-hydroxyquinoline in a flow injection system coupled to an inductively coupled plasma optical emission spectrometer, Spectrochimica Acta Part B: Atomic Spectroscopy. 58 (2003) 43-50. doi:10.1016/S0584-8547(02)00215-X.

[12] L.O.B. Silva, L.A. Portugal, E. Palacio, L. Ferrer, V. Cerdà, S.L.C. Ferreira, Multicommuted flow system for cadmium determination in natural water by cold vapour atomic absorption spectrometry, J. Anal. At. Spectrom. 29 (2014) 2398-2404. doi:10.1039/C4JA00305E.

[13] A.C.M. Aleluia, F.A. de Santana, G.C. Brandao, S.L.C. Ferreira, Sequential determination of cadmium and lead in organic pharmaceutical formulations using high-resolution continuum source graphite furnace atomic absorption spectrometry, Microchemical Journal. 130 (2017) 157-161. doi:10.1016/j.microc.2016.09.001.

[14] J. Ruzicka, Lab-on-valve: universal microflow analyzer based on sequential and bead injection, The Analyst. 125 (2000) 1053-1060. doi:10.1039/b001125h.

[15] S.S.M.P. Vidigal, I.V. Tóth, A.O.S.S. Rangel, Sequential injection lab-on-valve platform as a miniaturisation tool for solid phase extraction, Anal. Methods. 5 (2013) 585-597. doi:10.1039/C2AY26322J. 


\section{ACCEPTED MANUSCRIPT}

[16] I.C. Santos, R.B.R. Mesquita, A.O.S.S. Rangel, Micro solid phase spectrophotometry in a sequential injection lab-on-valve platform for cadmium, zinc, and copper determination in freshwaters, Analytica Chimica Acta. 891 (2015) 171-178. doi:10.1016/j.aca.2015.08.021.

[17] A. González, R.B.R. Mesquita, J. Avivar, T. Moniz, M. Rangel, V. Cerdà, A.O.S.S. Rangel, Microsequential injection lab-on-valve system for the spectrophotometric biparametric determination of iron and copper in natural waters, Talanta. (2017). doi:10.1016/j.talanta.2017.02.055.

[18] I.C. Santos, R.B.R. Mesquita, A.O.S.S. Rangel, Screening of cadmium and lead in potentially contaminated waters using a spectrophotometric sequential injection labon-valve methodology, Talanta. 143 (2015) 359-365. doi:10.1016/j.talanta.2015.05.005.

[19] N.P. Macdonald, J.M. Cabot, P. Smejkal, R.M. Guijt, B. Paull, M.C. Breadmore, Comparing microfluidic performance of 3D printing platforms, Anal. Chem. (2017). doi:10.1021/acs.analchem.7b00136.

[20] C. Chen, B.T. Mehl, A.S. Munshi, A.D. Townsend, D.M. Spence, R.S. Martin, 3Dprinted microfluidic devices: fabrication, advantages and limitations-a mini review, Anal. Methods. 8 (2016) 6005-6012. doi:10.1039/C6AY01671E.

[21] N. Bhattacharjee, A. Urrios, S. Kang, A. Folch, The upcoming 3D-printing revolution in microfluidics, Lab Chip. 16 (2016) 1720-1742. doi:10.1039/C6LC00163G.

[22] A.A. Yazdi, A. Popma, W. Wong, T. Nguyen, Y. Pan, J. Xu, 3D printing: an emerging tool for novel microfluidics and lab-on-a-chip applications, Microfluidics and Nanofluidics. 20 (2016). doi:10.1007/s10404-016-1715-4.

[23] C. Calderilla, F. Maya, V. Cerdà, L.O. Leal, 3D printed device including disk-based solid-phase extraction for the automated speciation of iron using the multisyringe flow 


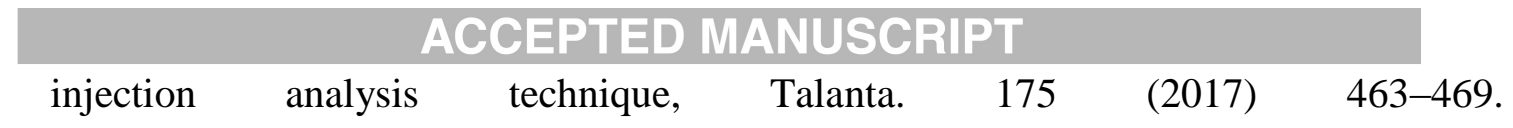
doi:10.1016/j.talanta.2017.07.028.

[24] E. Mattio, F. Robert-Peillard, C. Branger, K. Puzio, A. Margaillan, C. Brach-Papa, J. Knoery, J.-L. Boudenne, B. Coulomb, 3D-printed flow system for determination of lead in natural waters, Talanta. $168 \quad$ (2017) 298-302. doi:10.1016/j.talanta.2017.03.059.

[25] J.F. García-Reyes, P. Ortega-Barrales, A. Molina-Díaz, Sensing of trace amounts of cadmium in drinking water using a single fluorescence-based optosensor, Microchemical Journal. 82 (2006) 94-99. doi:10.1016/j.microc.2005.11.001.

[26] M. Soibinet, V. Souchon, I. Leray, B. Valeur, Rhod-5N as a Fluorescent Molecular Sensor of Cadmium(II) Ion, Journal of Fluorescence. 18 (2008) 1077-1082. doi:10.1007/s10895-008-0352-z.

[27] A.F. Shaaban, D.A. Fadel, A.A. Mahmoud, M.A. Elkomy, S.M. Elbahy, Removal of $\mathrm{Pb}(\mathrm{II}), \mathrm{Cd}(\mathrm{II}), \mathrm{Mn}(\mathrm{II})$, and $\mathrm{Zn}(\mathrm{II})$ using iminodiacetate chelating resin by batch and fixed-bed column methods, Desalination and Water Treatment. 51 (2013) 5526-5536. doi:10.1080/19443994.2012.758059.

[28] R. Prribil, V. Veselý, The extraction separation of cadmium and zinc and their complexometric determination in the presence of other elements, Collect. Czech. Chem. Commun., CCCC. 37 (1972) 13-21. doi:10.1135/cccc19720013.

[29] M. Ohkubo, A. Miyamoto, M. Shiraishi, Heavy metal chelator TPEN attenuates fura-2 fluorescence changes induced by cadmium, mercury and methylmercury, Journal of Veterinary Medical Science. 78 (2016) 761-767.

[30] C.A. Blindauer, M.T. Razi, S. Parsons, P.J. Sadler, Metal complexes of N,N,N',N'tetrakis(2-pyridylmethyl)ethylenediamine (TPEN): Variable coordination numbers and geometries, Polyhedron. 25 (2006) 513-520. doi:10.1016/j.poly.2005.08.019. 


\section{ACCEPTED MANUSCRIPT}

[31] A.N. Anthemidis, K.-I. G. Ioannou, Development of a sequential injection dispersive liquid-liquid microextraction system for electrothermal atomic absorption spectrometry by using a hydrophobic sorbent material: Determination of lead and cadmium in natural waters, Analytica Chimica Acta 668 (2010) 35-40. doi:10.1016/j.aca.2009.10.063.

[32] Z.H. Wang, Z.P. Zhang, Z.P. Wang, L.W. Liu, X.P. Yan, Acrylic acid grafted polytetrafluoroethylene fiber as new packing for flow injection on-line microcolumn preconcetration coupled with falme atomic absorption spectrometry for determination of lead and cadmium in environmental and biological samples, Analytica Chimie Acta 514 (2004) 151-157. doi:10.1016/j.aca.2004.03.049.

[33] A. N.Anthemidis, G.G.S. Xidia, M. Miró, On-line sorptive preconcentration platform incorporating a readily exchangeable Oasis HLB extraction micro-cartridge for trace cadmium and lead determination by flow injection-flame atomic absorption spectrometry, Microchemical Journal $98 \quad$ (2011) 66-71. doi.org/10.1016/j.microc.2010.11.007.

[34] B. Nimwong, S. Chuanuwatanakul, O. Chailapakul, W. Dungchai, S. Motomizu, Online preconcentration and determination of lead and cadmium by sequential injection/anodic stripping voltammetry, Talanta $96 \quad$ (2012) 75-81. doi:10.1016/j.talanta.2012.03.057.

[35] W. Wonsawatt, S. Chuanuwatanakul, W. Dungchai, E. Punrat, S. Motomizu, O. Chailapakul, Graphene-carbon paste electrode for cadmium and lead ion monitoring in a flow-based system, Talanta 100 (2012) 282-289. doi:10.1016/j.talanta.2012.07.045.

[36] J.F.van Staden, R.E.Taljaard, Determination of Lead(II), Copper(II), Zinc(II), Cobalt(II), Cadmium(II), Iron(III), Mercury(II) using sequential injection extractions, Talanta64 (2004) 1203-1212. doi.org/10.1016/j.talanta.2004.06.020. 


\section{ACCEPTED MANUSCRIPT}

[37] Directive 2008/105/EC of the European parliament and of the council of 16 December 2008 on environmental quality standards in the field of water policy, amending and subsequently repealing Council Directives 82/176/EEC, 83/513/EEC, 84/156/EEC, 84/491/EEC, 86/280/EEC and amending Directive 2000/60/EC of the European Parliament and of the Council. http://data.europa.eu/eli/dir/2008/105/oj.

[38] V. Guzsványa, H. Nakajima, N. Soh, K. Nakano, T. Imato, Antimony-film electrode for the determination of trace metals by sequential-injection analysis/anodic stripping voltammetry, Analytica Chimica Acta $658 \quad$ (2010) 12-17. doi:10.1016/j.aca.2009.10.049.

[39] S. Suteerapataranon, J. Jakmunee, Y. Vaneesorn, K. Grudpan, Exploiting flow injection and sequential injection anodic stripping voltammetric systems for simultaneous determination of some metals, Talanta 58 (2002) 1235-1242.

[40] E.L. Silva, P. dos Santos Roldan, Simultaneous flow injection preconcentration of lead and cadmium using cloud point extraction and determination by atomic absorption spectrometry, Journal of Hazardous Materials $161 \quad$ (2009) 142-147. doi:10.1016/j.jhazmat.2008.03.100.

[41] T. Yamane, Y. Yamaguchi, Complex formation of 2-(5-nitro-2-pyridylazo)-5-(Npropyl-N-sulfo-propylamino)phenol with lead, cadmium and manganese for their sensitive spectrophotometric detection in flow injection and ion chromatography systems, Analytica Chimie Acta 345 (1997) 139-146.

[42] W. Siriangkhawut, S. Pencharee, K. Grudpan, J. Jakmunee, Sequential injection monosegmented flow voltammetric determination of cadmium and lead using a bismuth film working electrode, Talanta $79 \quad$ (2009) 1118-1124. doi:10.1016/j.talanta.2009.03.032. 

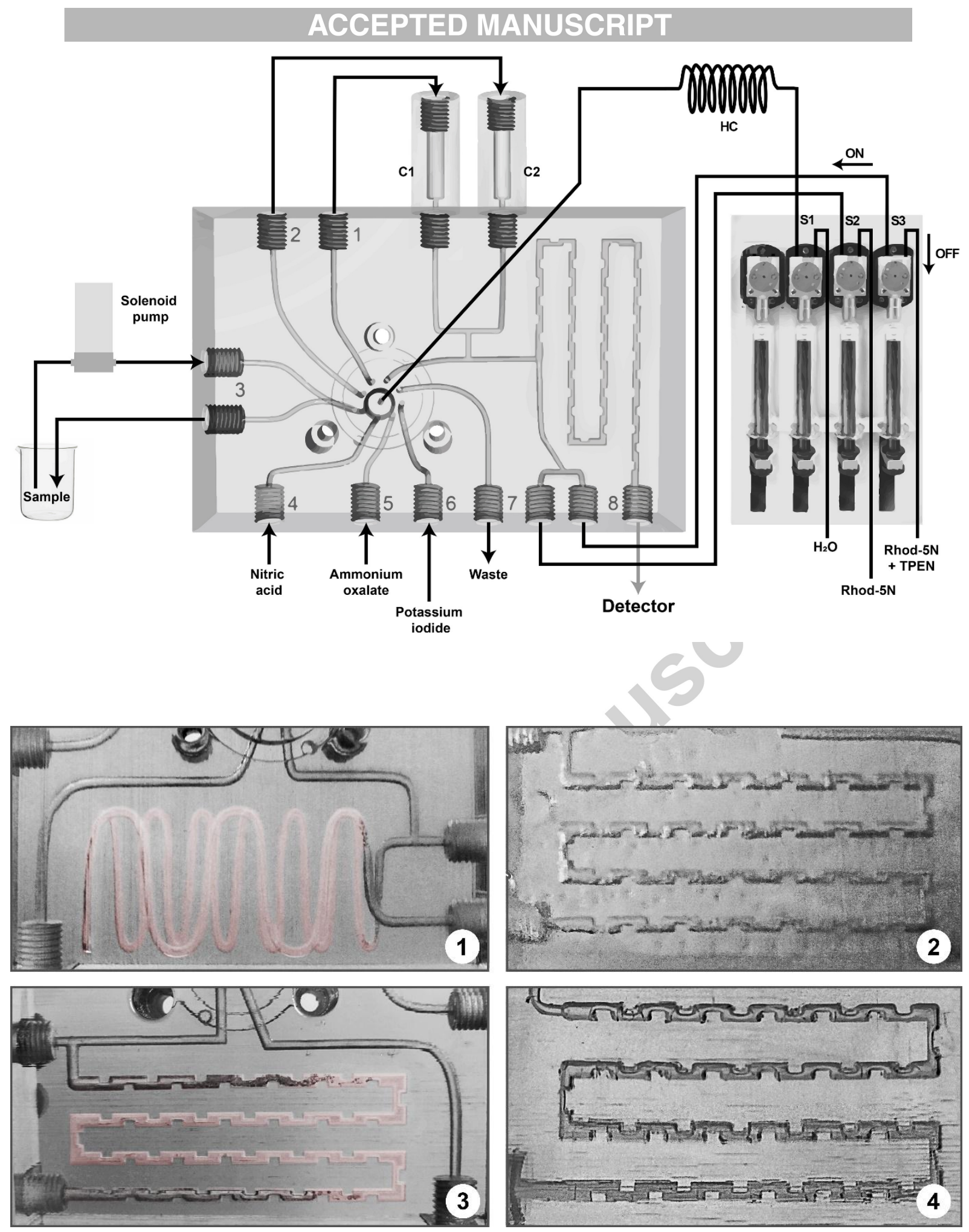


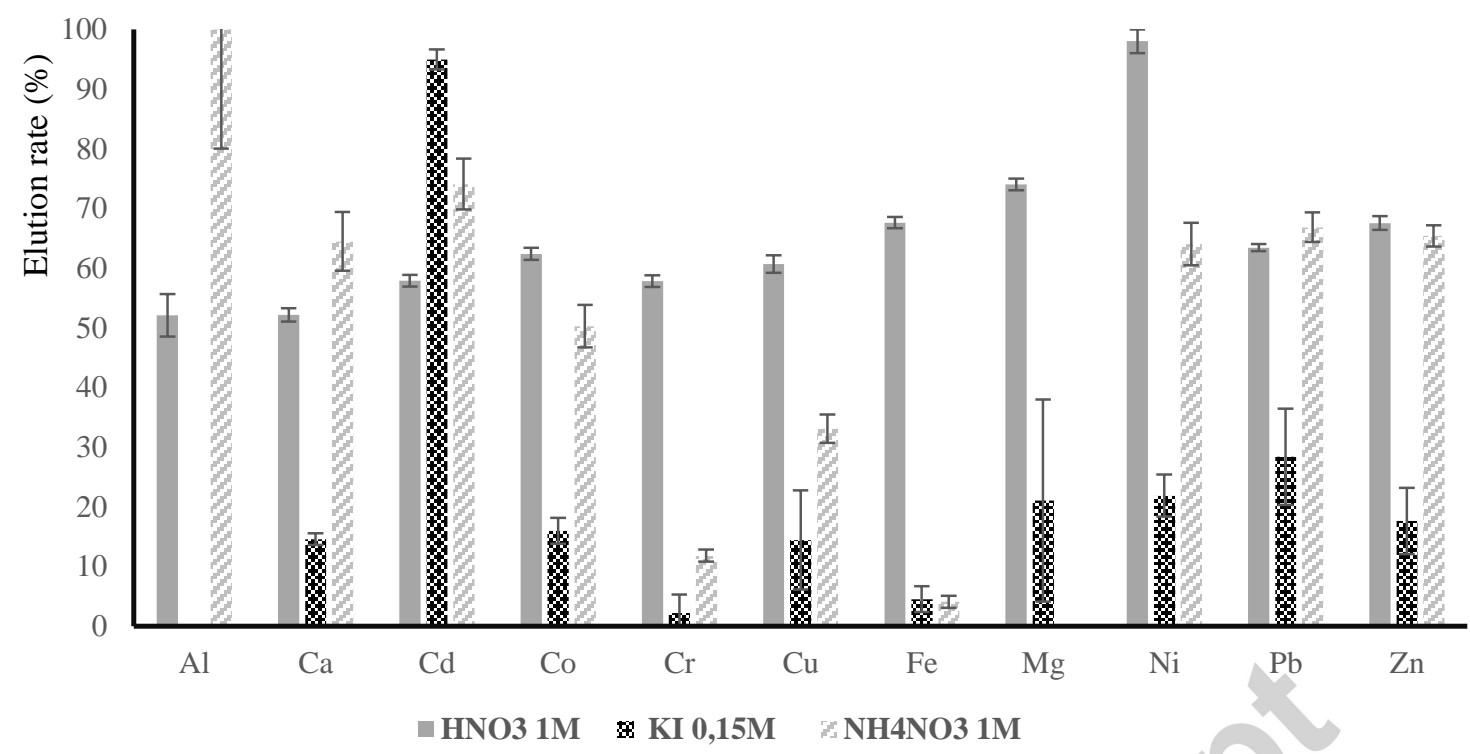

Table 1. Flow procedure for cadmium and lead determination.

\begin{tabular}{|c|c|c|c|c|c|c|c|}
\hline & Step & $\begin{array}{l}\text { LOV } \\
\text { position }\end{array}$ & $\begin{array}{l}\text { Volume } \\
(\mathrm{mL})\end{array}$ & $\begin{array}{l}\text { Flow- } \\
\text { rate } \\
(\mathrm{mL} / \\
\mathrm{min})\end{array}$ & $\mathrm{S} 1$ & S2 & S3 \\
\hline & Conditioning TrisKem $\mathrm{Pb}$ resin $(\mathrm{C} 1)$ & & & & & & \\
\hline 1 & Loading $\mathrm{HNO}_{3}$ & & 4 & 4 & $\mathrm{ON}$ & OFF & OFF \\
\hline \multirow[t]{2}{*}{2} & Dispensing $\mathrm{HNO}_{3}$ towards $\mathrm{C} 1$ & & 4 & 4 & ON & OFF & OFF \\
\hline & Sample loading & & & & & & \\
\hline 3 & Loading sample into $\mathrm{HC}$ & 3 & 5 & 4 & $\mathrm{ON}$ & OFF & OFF \\
\hline 4 & Dispensing sample into $\mathrm{C} 1$ & 1 & 5 & 4 & ON & OFF & OFF \\
\hline 5 & Loading previous sample into $\mathrm{HC}$ & 8 & 5 & 4 & ON & OFF & OFF \\
\hline \multirow[t]{2}{*}{6} & Dispensing previous sample into $\mathrm{C} 2$ & 2 & 5 & 4 & ON & OFF & OFF \\
\hline & $\begin{array}{l}\text { Elution of Amberlite® IR } 120(\mathrm{C} 2) \text { and } \\
\text { cadmium detection }\end{array}$ & & & & & & \\
\hline 7 & Loading potassium iodide into $\mathrm{HC}$ & 6 & 4 & 4 & ON & OFF & OFF \\
\hline \multirow[t]{2}{*}{8} & $\begin{array}{l}\text { Simultaneous dispensing of potassium iodide } \\
\text { into } 22 \text { and Rhod- } 5 \mathrm{~N} \text { into mixing coil }\end{array}$ & 2 & 4 & 4 & ON & ON & OFF \\
\hline & Sample loading through & & & & & & \\
\hline 9 & Loading sample into $\mathrm{HC}$ & 3 & 5 & 4 & ON & OFF & OFF \\
\hline 10 & Dispensing sample into $\mathrm{C} 1$ & 1 & 5 & 4 & ON & OFF & OFF \\
\hline 11 & Loading previous sample into $\mathrm{HC}$ & 8 & 5 & 4 & $\mathrm{ON}$ & OFF & OFF \\
\hline 12 & Dispensing previous sample into $\mathrm{C} 2$ & 2 & 5 & 4 & ON & OFF & OFF \\
\hline
\end{tabular}


Interferences integration for $\mathrm{Cd}$

13 Loading potassium iodide

6

4

ON OFF OFF

Simultaneous dispensing potassium iodide

14 into $\mathrm{C} 2$ and Rhod-5N with TPEN into mixin coil

\begin{tabular}{|c|c|c|c|c|c|c|c|}
\hline & Interferences elimination for $\mathrm{Pb}$ & & & & & & \\
\hline 15 & Loading $\mathrm{HNO}_{3}$ & 4 & 4 & 4 & $\mathrm{ON}$ & $\mathrm{OFF}$ & OFF \\
\hline \multirow[t]{2}{*}{16} & Dispensing $\mathrm{HNO}_{3}$ to $\mathrm{C} 1$ & 1 & 4 & 4 & $\mathrm{ON}$ & OFF & OFF \\
\hline & Elution of TrisKem $\mathrm{Pb}(\mathrm{C} 1)$ and lead detectio & & & & & & \\
\hline 17 & Loading ammonium oxalate & 5 & 4 & 4 & $\mathrm{ON}$ & OFF & OFF \\
\hline 18 & $\begin{array}{l}\text { Simultaneous dispensing ammonium oxalate } \\
\text { into } \mathrm{C} 1 \text { and Rhod-5N into mixing coil }\end{array}$ & 1 & 4 & 4 & $\mathrm{ON}$ & $\mathrm{ON}$ & OFF \\
\hline
\end{tabular}

Table 2. Comparison of main analytical features of flow systems for cadmium and lead determination in water samples.

\begin{tabular}{|c|c|c|c|c|c|c|c|}
\hline $\begin{array}{l}\text { Flow } \\
\text { system }\end{array}$ & Detection & $\begin{array}{c}\mathrm{Pb} \\
\text { Range } \\
\left(\mu \mathrm{g} . \mathrm{L}^{-1}\right)\end{array}$ & $\begin{array}{c}\mathrm{Pb} \\
\mathrm{LOD} \\
\left(\mu \mathrm{g} . \mathrm{L}^{-1}\right)\end{array}$ & $\begin{array}{c}\mathrm{Cd} \\
\text { Range } \\
\left(\mu \mathrm{g} . \mathrm{L}^{-1}\right)\end{array}$ & $\begin{array}{c}\mathrm{Cd} \\
\mathrm{LOD} \\
\left(\mu \mathrm{g} . \mathrm{L}^{-1}\right)\end{array}$ & Matrix & Ref. \\
\hline $\begin{array}{l}\text { SI- } \\
\text { DLLME }\end{array}$ & ETAAS & $\begin{array}{c}0.04- \\
1.5\end{array}$ & 0.01 & $\begin{array}{l}0.006- \\
0.15\end{array}$ & 0.002 & Natural waters & {$[31]$} \\
\hline SI & ASV & $0.5-15$ & 0.01 & $0.5-15$ & 0.01 & Tap water & {$[34]$} \\
\hline SI & $\begin{array}{l}\text { CV or } \\
\text { SWASV }\end{array}$ & $0.1-50$ & 0.04 & $0.1-50$ & 0.07 & Tap water & {$[35]$} \\
\hline $\begin{array}{l}\text { MSFIA- } \\
\text { LOV }\end{array}$ & Fluorimetry & $0.2-15$ & 0.17 & $0.2-20$ & 0.20 & Natural waters & $\begin{array}{l}\text { This } \\
\text { work }\end{array}$ \\
\hline FI & FAAS & $2.5-250$ & 0.26 & $0.5-60$ & 0.1 & $\begin{array}{l}\mathrm{HNO}_{3} \text { extracts } \\
\text { of biological } \\
\text { and } \\
\text { environmental } \\
\text { samples }\end{array}$ & {$[32]$} \\
\hline FI & FAAS & $3.1-200$ & 0.92 & $0.3-12$ & 0.09 & Water samples & [33] \\
\hline SI & ASV & $4.7-120$ & 1.5 & $5.2-110$ & 1.7 & Tap water & {$[38]$} \\
\hline FI & ASV & $10-100$ & 2 & $10-30$ & 1 & $\begin{array}{l}\text { Wastewater } \\
\text { samples }\end{array}$ & [39] \\
\hline
\end{tabular}




\begin{tabular}{|c|c|c|c|c|c|c|c|}
\hline \multirow[b]{2}{*}{ FI } & \multicolumn{6}{|c|}{ ACCEPTED MANUSCRIPT } & \multirow[b]{2}{*}[40]{} \\
\hline & CPE-FAAS & $50-250$ & 4.5 & $5-25$ & 0.75 & Water samples & \\
\hline FI & $\begin{array}{l}\text { IC-PCR- } \\
\text { PAD }\end{array}$ & $0-300$ & 4.8 & $0-150$ & 1.9 & $\begin{array}{l}\text { Food samples } \\
\text { after microwave } \\
\text { digestion }\end{array}$ & {$[41]$} \\
\hline SI-MSFA & ASV & $10-100$ & 6.9 & $10-100$ & 1.4 & Water samples & {$[42]$} \\
\hline SI & ASV & $10-100$ & 10 & $10-70$ & 6 & $\begin{array}{l}\text { Wastewater } \\
\text { samples }\end{array}$ & {$[39]$} \\
\hline SI-LOV & Spectrometry & $\begin{array}{l}500- \\
10000\end{array}$ & 56 & $\begin{array}{c}500- \\
10000\end{array}$ & 34 & $\begin{array}{l}\text { Contaminated } \\
\text { waters }\end{array}$ & {$[18]$} \\
\hline SI & Spectrometry & $\begin{array}{l}1000- \\
20000\end{array}$ & - & $\begin{array}{l}1000- \\
5000\end{array}$ & - & Tap water & {$[36]$} \\
\hline
\end{tabular}

FI, flow injection; SI, sequential injection; SI-MSFA, sequential injection-monosegmented flow analysis; SI-DLLME, sequential injection-dispersive liquid-liquid microextraction; SILOV, sequential injection-lab-on-valve; MSFIA-LOV, multisyringe flow injection analysislab-on-valve; SV, anodic stripping voltammetry; CV, cyclic voltammetry; SWASV, square wave anodic stripping voltammetry; FAAS, flame atomic absorption spectrometry; IC-PCR$\mathrm{PAD}$, ion chromatography-post column reaction-photodiode array detector, ETAAS, electrothermal atomic absorption spectrometry; CPE-FAAS, cloud point extraction-flame atomic absorption spectrometry.

Table 3. Lead and cadmium determination in natural waters with 3D printed LOV-MSFIA system.

\begin{tabular}{ccccc}
\hline \multirow{2}{*}{ Samples } & \multicolumn{2}{c}{ Lead $(\mu \mathrm{g} / \mathrm{L})$} & \multicolumn{2}{c}{ Cadmium $(\mu \mathrm{g} / \mathrm{L})$} \\
\cline { 2 - 5 } & 3D LOV-MSFIA & \multirow{2}{*}{ AAS } & 3D LOV-MSFIA & $\begin{array}{c}\text { 3D LOV-MSFIA } \\
\text { Spiked to 5 } \mu \mathrm{g} / \mathrm{L}\end{array}$ \\
\hline Spring water & $11.7 \pm 0.4$ & $10.9 \pm 0.5$ & $<$ LOD & $4.4 \pm 0.6$ \\
City canal water & $6.9 \pm 0.5$ & $7.4 \pm 0.6$ & $<$ LOD & $4.1 \pm 0.3$ \\
Well water & $11.1 \pm 0.3$ & $11.8 \pm 0.4$ & $<$ LOD & $4.5 \pm 0.5$ \\
\hline
\end{tabular}


Highlights

- A 3D-printed LOV-MSFIA system is presented.

- $\mathrm{Pb}^{2+}$ and $\mathrm{Cd}^{2+}$ can be quantified between 0.2 and $15 \mu \mathrm{g} . \mathrm{L}^{-1}$.

- The LODs obtained (0.20 and $0.17 \mu \mathrm{g} . \mathrm{L}^{-1}$ for cadmium and lead respectively) are lower than the MAC-EQS as defined by the European regulations.

- 3D printing of LOV units opens new perspectives for the design of more complex LOV systems.

Graphical abstract:

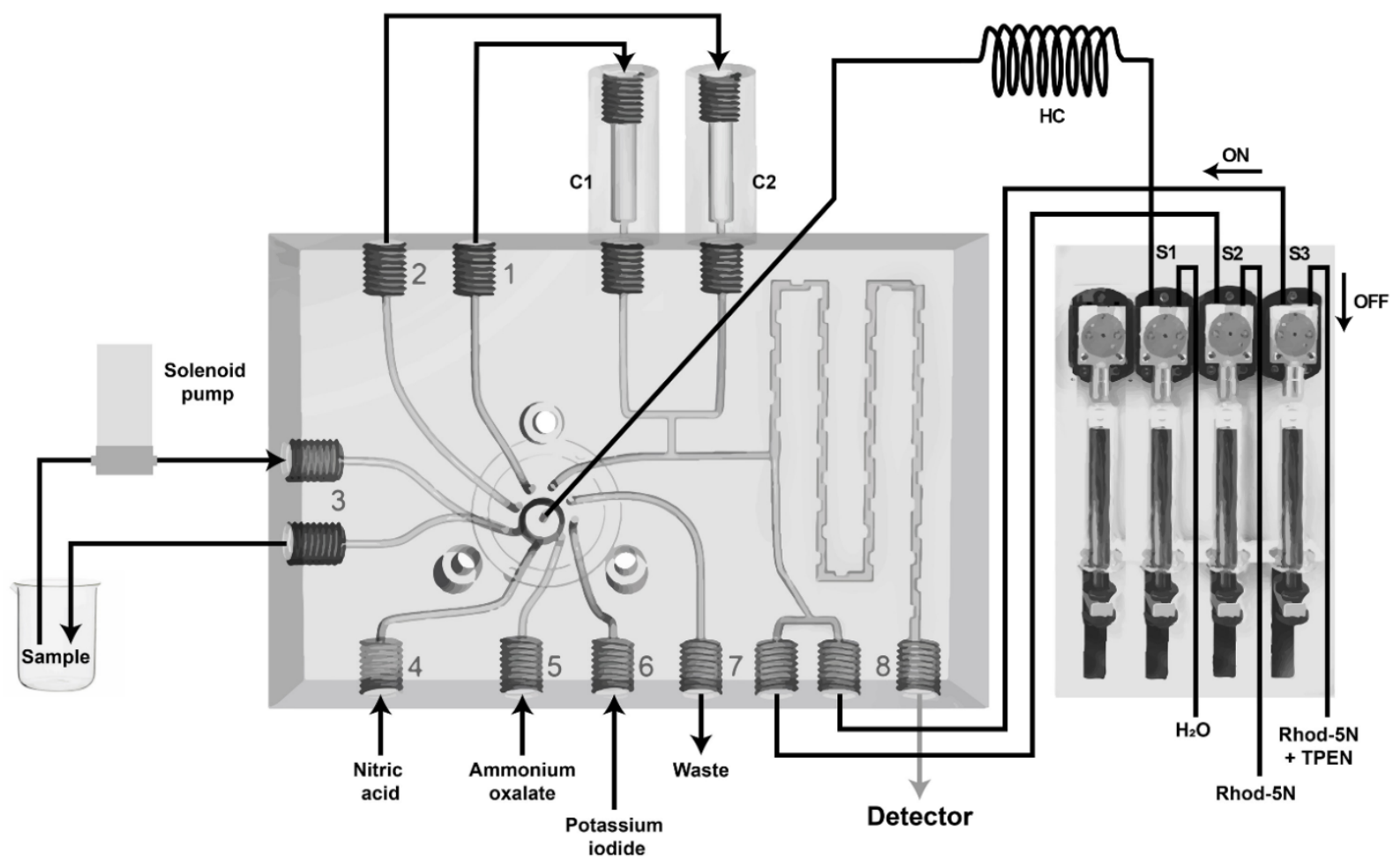

